\title{
A utilização do kit para higiene bucal no protocolo de pacientes hospitalizados
}

\author{
The utilization of the kit for oral hygiene in the protocol of hospitalized patients
}

\section{La actualización del kit para la higiene bucal en el protocolo de pacientes hospitalizados}

Jorge Sá Elias Nogueira ${ }^{1 *}$, Marcelo Newton Carneiro ${ }^{1}$, Dóris Kós Burlamaqui de Miranda ${ }^{1}$, Ricardo Roberto de Souza Fonseca ${ }^{1}$, Henrique de Mello Rodrigues ${ }^{1}$, Kawanne Ferreira Moraes Medeiros ${ }^{1}$, Beatriz Melo Campos ${ }^{1}$, Camila Lopes Conde ${ }^{1}$, Stefany Alexsandra Lemos Menezes Costa Braga1.

\section{RESUMO}

Objetivo: Relatar a experiência prática de um kit de higiene bucal de baixo custo criado para pacientes hospitalizados. Relato de experiência: Trata-se de um relato em uma unidade hospitalar do município de Belém-PA, onde foram escolhidos dois pacientes internados para apresentarmos e entregarmos o kit de higiene bucal de baixo custo composto por escova dental, dentifrício, fio dental, clorexidina, gaze, canudinho, papel toalha e sacos descartáveis. Foi observado que os mesmos não possuíam todos os itens necessários para limpeza da cavidade bucal, nem um local adequado e de fácil acesso para guarda-los, constatou-se que eles nunca receberam qualquer instrução sobre a maneira correta de higienização bucal e como armazenar os itens após o uso. Em seguida, eles foram instruídos sobre a função de cada item, assim como sua devida utilização para obtenção de eficiência máxima. Considerações finais: É viável aquisição, visto que, a carência de utensílios necessários para a higienização contribui para infecção hospitalar e doenças do trato respiratório.

Palavras-chave: Higiene bucal, Gengivite, Clorexidina.

\section{ABSTRACT}

Objective: To report the practical experience of a oral hygiene kit designed for hospitalized. Experience report: It is about of a report at a hospital unit of the county of Belém-PA, where two inpatients were chosen for us to present and to hand the oral hygiene kit of a low cost composed by toothbrush, dentifrice, dental floss, clorexidine, gauze, plastic straw, paper towel and disposable bags. It was observed that the patients didn't have all the necessary items for the clean of the buccal cavity, nor a proper and easy access place to stow them, it was verified that the patients never recieved any instruction about the correct way of buccal hygiene and how to store the items post use. Then, they were instructed about the function of each item, as well as its proper using to obtain maximum effiency. Final considerations: It is viable aquisition, whereas, the shortage of necessary utensils to sanitation contributes for hospital infection and deceases of the respiratory tract.

Keywords: Oral hygiene, Gingivitis, Chlorhexidine.

\section{RESUMEN}

Objetivo: Narrar la experiencia práctica de un kit de higiene bucal de bajo costo creado para pacientes hospitalizados. Informe de experiencia: Se trata de un relato en una unidad hospitalaria del municipio de Belém-PA donde fueron escojidos dos pacientes internados para presentarnos y entregarnos el kit de

\footnotetext{
${ }^{1}$ Centro Universitário do Estado do Pará (CESUPA), Belém - PA. *E-mail: jorge.nogueira@prof.cesupa.br
} 
higiene bucal de bajo costo compuesto por cepillo de diente, pasta dental, hilo dental, clorhexidina, gasa, cañudo, papel toalla y bolsas desechables. Fue observado que los mismos no peseen todos los artículos necesarios para limpieza de la cavidad bucal, ni un lugar adecuado y de facil acceso para guardarlos, se constató que ellos nunca recibieron cualquier tipo de instrucción sobre la manera correcta de higiene bucal y como almacenar los artículos despues del uso. En seguida, ellos fueron instruidos sobre la función de cada artículo, así como tambén su debido uso para obtener eficiencia máxima. Consideraciones finales: Es viable la adquisición del kit, visto que, la falta de utencilios necesarios para la higienización contribuyen para infección hospitalaria y enfermedades de trato respiratorio.

Palabras clave: Higiene bucal, Gingivitis, Clorhexidina.

\section{INTRODUÇÃO}

A odontologia hospitalar é uma especialidade que vem conquistando seu espaço em âmbito internacional, razão por que é de suma importância sua atuação na equipe multidisciplinar, para prevenção e tratamento de patologias. Há diversas doenças que começam ou têm sinais na cavidade bucal; além disso, pacientes em unidade de terapia intensiva (UTI) requerem mais cuidados e conhecimento de um cirurgião-dentista $(C D)$, visto que, na cavidade bucal, encontram-se fungos, vírus e bactérias. Consequentemente, existe um grande índice na literatura sobre associação entre bactérias e a pneumonia nosocomial em pacientes internados na UTI. Esse fenômeno abrange de 10\% a 15\% das infecções hospitalares e destas $20 \%$ a $50 \%$ evoluem para óbito, além de causar influência significativa nos custos de internação, pois podem agir como um agente agravador no quadro do paciente, aumentando em média de 7 a 9 dias de internação (NETO JM et al., 2019; GOMES SF e ESTEVES MC, 2012).

Tendo em vista que o controle do biofilme previne a cárie e a doença periodontal, a qual é um possível fator de risco para doenças sistêmicas e alterações cardiovasculares, como por exemplo a Síndrome de Resposta Inflamatória Sistêmica e endocardite bacteriana. Devem ser utilizados métodos químicos e mecânicos de higiene bucal (HB), escolhendo-se a técnica de escovação mais efetiva de acordo com o perfil de cada paciente. Com isso, é necessário orientá-lo, assim como a seu acompanhante, destacando que os tratamentos preventivos são imprescindíveis para saúde bucal. A atuação do CD na rotina hospitalar ainda é escassa, mesmo que ele seja o profissional indicado para a elaboração de protocolos e supervisão (MENEZES ML et al., 2020; BARBOSA LM et al., 2020)

Somado a isso, no final de 2019, houve o surgimento do novo tipo de coronavírus (Sars-Cov-2), o qual é responsável pelo agravamento de doenças sistêmicas e respiratórias. Consequentemente, obteve-se um aumento significativo de pacientes internados, principalmente em UTI, alguns com manifestações na cavidade bucal. Portanto, vê-se assim a necessidade de o CD não apenas para realizar os procedimentos odontológicos comuns, mas também para combater a disseminação desse vírus pelas vias aéreas (FRANCO AB e FRANCO AG, 2020).

O objetivo principal deste projeto foi a conscientização sobre a importância dos cuidados com a saúde bucal dos pacientes internados, idealização e instalação do kit de higiene bucal em local acessível ao paciente ou ao acompanhante.

\section{RELATO DE EXPERIÊNCIA}

Por mais de meio século o hospital de pronto socorro foi única opção de atendimento de urgência e emergência para o estado do Pará, e em muitas ocasiões, para municípios de estados vizinhos. Daí surgia a necessidade de permanência ali por vários dias, por conta das mais diversas patologias, como relatado por Nogueira ES, et al. (2014), mostrando-se a permanência de pacientes por período superior a 20 dias.

Frente ao exposto, surgiu a necessidade de criação de um kit de HB para os pacientes internados por período superior a $24 \mathrm{~h}$, de modo a ofertar os itens necessários para a higiene, com acomodação segura para possibilitar menor contaminação por microrganismos do ambiente hospitalar. Isso, porque muitos doentes não traziam ou não tinham material para esse fim e, consequentemente, permaneciam ali sem a 
realização de higiene necessária; ou quando possuíam, não tinham como dar a devida importância no acondicionamento. É importante também citar os pacientes internados nas UTIs e diversas clínicas com incapacidades motoras, que também necessitam dos mesmos cuidados e, às vezes sem acompanhantes, devem receber higiene pela equipe de saúde.

Para o desenvolvimento do projeto, foi escolhido um hospital em um município do estado do Pará. Logo na chegada, os acadêmicos foram direcionados a fim de receber as instruções iniciais para realização das atividades. Por se tratar de um período de pandemia global, com grande número de casos da cidade de Belém-PA, foram reforçados todos os procedimentos de segurança, conforme orientações da Organização Mundial da Saúde (OMS), bem como os procedimentos locais do hospital, com utilização de todos os EPIs para trânsito nas suas dependências.

Após a orientação, o primeiro paciente selecionado foi do sexo masculino, com idade aparente entre 15 e 20 anos. O segundo paciente selecionado foi do sexo feminino, com idade aparente entre 20 e 30 anos. Ao indagar se os pacientes já haviam recebido algum tipo de orientação sobre procedimentos de saúde bucal, os mesmos responderam que nunca haviam sido orientados.

Então apresentamos e entregamos a eles os kits de HB com escova de dente, enxaguante bucal e fio dental, instruindo-os sobre a função de cada item, assim como sobre sua devida utilização para obtenção de eficiência máxima. A receptividade dos pacientes foi satisfatória e as orientações passadas foram absorvidas para continuidade dos cuidados com a saúde bucal durante a vida. Desta forma, podemos observar que mesmo pessoas adultas não possuem o conhecimento básico necessário para cuidados com a saúde bucal, o que explica a falta de orientação, contribuindo assim para patologias causadas por má ou falta de HB.

O kit é composto por alguns itens indispensáveis à $\mathrm{HB}$, devendo ser fixado em superfícies lisas e ficando em localização acessível para o paciente, seu acompanhante ou profissional de saúde, o qual será responsável pela sua higienização bucal, de modo que não interfira na ergonomia, biossegurança e movimentação da equipe de saúde, os itens descartáveis contidos no produto deverão ser renovados pela equipe responsável, assim como deverá ser feita sua desinfecção (Figura 1).

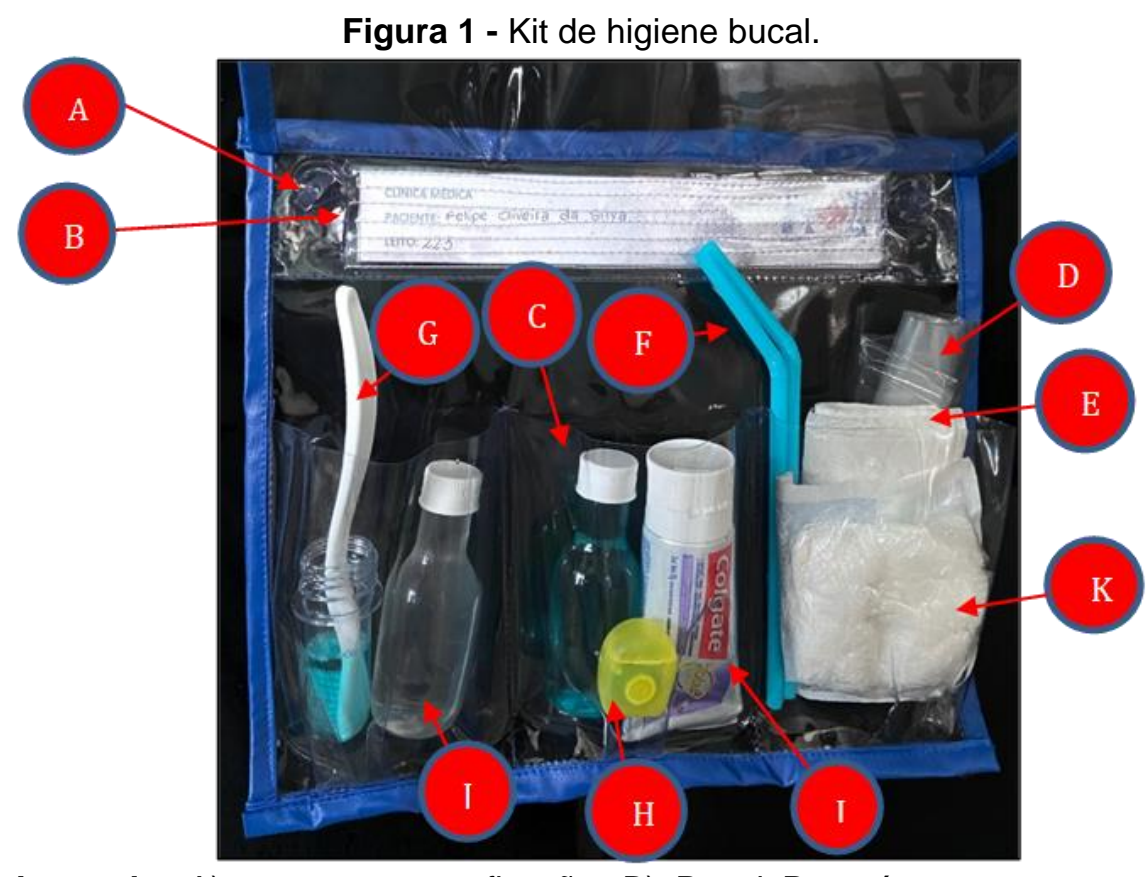

Legenda: A) ventosas para fixação; B) Papel Paraná para sustentação com rótulo de identificação do paciente; C) recipiente com clorexidina; D) saco plástico; E) lenço de papel; F) canudo descartável; G) escova dental submersa em clorexidina no recipiente plástico; H) fio dental; I) dentifrício; J) Recipiente plástico para água; K) Gazes. Fonte: Nogueira JSE, et al., 2021. 
Tabela 1 - Previsão orçamentaria na elaboração do kit (valores consultados e atualizados em junho de 2021).

\begin{tabular}{|c|c|c|c|c|}
\hline Material & Quantidade & Preço Loja 1 & Preço Loja 2 & Preço Loja 3 \\
\hline $\begin{array}{c}\text { Plástico transparente } 0.30 \\
\text { CIPATEX }\end{array}$ & $\begin{array}{c}1 \text { Unidade } \\
(0,5 \mathrm{~m} \times 1,4 \mathrm{~m})\end{array}$ & $R \$ 12,95$ & $\mathrm{R} \$ 11,88$ & $\mathrm{R} \$ 16,00$ \\
\hline Ventosas de silicone com $50 \mathrm{~mm}$ & 2 unidades & $\mathrm{R} \$ 2,30$ & $\mathrm{R} \$ 2,60$ & $\mathrm{R} \$ 2,90$ \\
\hline Papel Paraná 27 X 4cm & 1 unidade & $\mathrm{R} \$ 0,52$ & $\mathrm{R} \$ 0,73$ & $\mathrm{R} \$ 0,54$ \\
\hline $\begin{array}{l}\text { Papel Sulfite A4 Chamequinho } \\
\text { pacote } 27 \times 4 \mathrm{~cm}\end{array}$ & 1 unidade & $\mathrm{R} \$ 0,035$ & $\mathrm{R} \$ 0,04$ & $\mathrm{R} \$ 0,06$ \\
\hline $\begin{array}{l}\text { Recipiente plástico PET cilíndrico } \\
50 \mathrm{ml}\end{array}$ & 2 unidades & $\mathrm{R} \$ 2,20$ & $\mathrm{R} \$ 2,38$ & $R \$ 2,40$ \\
\hline $\begin{array}{c}\text { Clorexidina } 0,12 \% \text { RIOHEX GARD- } \\
\text { RIOQUIMICA }\end{array}$ & $60 \mathrm{ml}$ & $R \$ 2,25$ & $\mathrm{R} \$ 2,60$ & $\mathrm{R} \$ 2,45$ \\
\hline Canudo descartável pacote & 1 unidade & $\mathrm{R} \$ 0,04$ & $\mathrm{R} \$ 0,05$ & $R \$ 0,055$ \\
\hline $\begin{array}{l}\text { Saco plástico descartável de } \\
10 \times 20 \mathrm{~cm}\end{array}$ & 5 unidades & $R \$ 0,19$ & $\mathrm{R} \$ 0,20$ & $R \$ 0,30$ \\
\hline $\begin{array}{c}\text { Guardanapo de papel KITCHEN } \\
\text { com } 22,7 \times 22,8 \mathrm{~cm}\end{array}$ & 5 unidades & $\mathrm{R} \$ 0,16$ & $\mathrm{R} \$ 0,20$ & $R \$ 0,25$ \\
\hline $\begin{array}{l}\text { Compressa de Gaze Esteril } \\
\text { CREMER com } 7,5 \mathrm{~cm} \times 7 \mathrm{~cm}\end{array}$ & 1 pacote & $\mathrm{R} \$ 0,60$ & $\mathrm{R} \$ 0,70$ & $\mathrm{R} \$ 0,75$ \\
\hline $\begin{array}{c}\text { Escova Dental adulto macia- } \\
\text { MEDFIO }\end{array}$ & 1 unidade & $\mathrm{R} \$ 0,70$ & $\mathrm{R} \$ 0,95$ & $\mathrm{R} \$ 0,84$ \\
\hline Mini tubete de acrílico com 8cm & 1 unidade & $\mathrm{R} \$ 0,50$ & $\mathrm{R} \$ 0,75$ & $\mathrm{R} \$ 0,80$ \\
\hline Fio dental HILLO de $25 \mathrm{~m}$ & 1 unidade & $\mathrm{R} \$ 1,29$ & $\mathrm{R} \$ 1,60$ & $\mathrm{R} \$ 1,75$ \\
\hline $\begin{array}{l}\text { Creme Dental Colgate Total } 12 \\
\text { Gum 50g }\end{array}$ & 1 unidade & $\mathrm{R} \$ 2,69$ & $\mathrm{R} \$ 2,79$ & $R \$ 3,00$ \\
\hline Custo total & & $R \$ 26,42$ & $\mathrm{R} \$ 27,47$ & $R \$ 32,09$ \\
\hline
\end{tabular}

Fonte: Nogueira JSE, et al., 2021.

O kit deverá ser todo em plástico transparente 0,30 CITAPEX, com capa para manter-se fechado, de tamanho horizontal de $25,3 \mathrm{~cm}$ e vertical de $30 \mathrm{~cm}$; deverá ser dividido em um compartimento horizontal e três compartimentos verticais, e ter duas ventosas de silicone com $50 \mathrm{~mm}$ para fixação. A parte superior do kit (horizontal) possui um compartimento de $27,5 \mathrm{~cm} \times 4,8 \mathrm{~cm}$, para alojar suporte em Papel Paraná de $27 \mathrm{~cm} \times 4 \mathrm{~cm}$, com rótulo para identificação do paciente feito com papel A4 $27 \mathrm{~cm} \times 4 \mathrm{~cm}$.

O primeiro compartimento vertical tem $7 \mathrm{~cm} \times 4 \mathrm{~cm}$ e contém a escova dental MEDFIO submersa em clorexidina $0,12 \%$, em um tubete de acrílico com $8 \mathrm{~cm}$, que tem como objetivo reduzir a carga microbiana da escova para níveis seguros, e um recipiente plástico de $60 \mathrm{ml} \mathrm{com} 11 \mathrm{~cm} \times 3,2 \mathrm{~cm}$ feito de Polietileno Tereftalato (PET), contendo água para bochecho. No segundo compartimento vertical de $11,2 \mathrm{~cm} \times 4 \mathrm{~cm}$, está um recipiente plástico de $60 \mathrm{ml}$ com $11 \mathrm{~cm} \times 3,2 \mathrm{~cm}$, Clorexidina 0,12\% RIOHEX GARD-RIOQUIMICA para bochecho, o fio dental HILLO de $25 \mathrm{~m}$ e Creme Dental Colgate Total 12 Gum de $90 \mathrm{~g}$. No terceiro compartimento vertical de $9,2 \mathrm{~cm} \times 4 \mathrm{~cm}$, está um canudo descartável para facilitar a sucção do antisséptico, sacos plásticos descartáveis de $10 \mathrm{~cm} \times 20 \mathrm{~cm}$ para expectoração do bochecho, guardanapos de papel de $22,7 \mathrm{~cm} \times 22,8 \mathrm{~cm}$ e compressa de Gaze com $7,5 \mathrm{~cm} \times 7 \mathrm{~cm}$.

\section{DISCUSSÃO}

Aguiar ASW, et al. (2010) relatam que atividades educacionais, como a de ação coletiva de escovação supervisionada nos leitos, são importantes e devem constar no cotidiano de pacientes hospitalizados, respeitando-se as limitações físicas e/ou neurológicas. Somado a isso, Nogueira ES, et al. (2014) em pesquisa realizada em um hospital de pronto socorro em Belém-PA, evidenciam que, de 415 prontuários de pacientes que permaneceram hospitalizados por mais de um dia, $71,8 \%$ não receberam quaisquer prescrições de HB. Destes, 34,69\% eram acometidos por distúrbios neurológicos e traumáticos, o que impossibilita a realização da $\mathrm{HB}$. 
Visto que favorece o acúmulo de placa bacteriana, resultando em patógenos que podem levar a gengivite, doença periodontal, cárie e até mesmo a pneumonia nosocomial. Dessa maneira é de extrema importância o estabelecimento de um protocolo com acompanhamento diário e evolução na assistência odontológica, prova disso é que os pacientes escolhidos para serem apresentados ao kit relataram nunca ter recebido instrução de HB.

Foi observado a carência de itens essenciais para higienização de pacientes e de um local adequado e acessível. Uma vez que as escovas dentais são um potente vetor de transmissão de infecção hospitalar por armazenamento em local inapropriado, podendo estar contaminadas por diversos microrganismos patogênicos. Após lavagem em água corrente, é uma boa e barata sugestão armazená-las em solução de clorexidina $0,12 \%$, o que proporcionaria sua sanificação e consequente redução da carga microbiana (QUEIROZ SF, et al., 2013).

Além disso, Busato CA, et al. (2015) relatam a imersão em hipoclorito de sódio 0,08\% durante 15 minutos após pesquisa in vitro, com excelente resultado, podendo esta substância ser usada em ambientes coletivos devido a seu fácil acesso, baixo custo e efetividade. Diante da impossibilidade de utilização de quaisquer agentes químicos, recomenda-se, para sanificação, que a escova deve ser lavada, enxugada e colocada em posição vertical em local apropriado. (GONÇALVES GH, et al., 2019).

Os dentifrícios são um importante produto terapêutico no auxílio do controle do biofilme e consequentemente da saúde bucal, principalmente do paciente hospitalizado, quando se encontra debilitado. O Triclosan tem-se mostrado um importante auxiliar antibacteriano, anti-inflamatório, quando associado ao gantrez e zinco diminui o biofilme e melhora a gengivite. (PINTO ATM, et al., 2013).

O dentifrício fluoretado é considerado como o meio mais razoável de usar o flúor, pois ao mesmo tempo em que o biofilme dental é desorganizado e removido pela escovação, o flúor é liberado no meio bucal, protegendo contra lesões de cárie. Em teste de laboratório sobre a atividade antimicrobiana de dentifrícios de diferentes marcas, contra cepas de referência de Streptococcus mutans e Staphylococcus aureus, verificou que o Malvatricin $\AA$, que contém extrato de Malva, e Colgate Total $12 \AA$, que contém Triclosan e Fluoreto de Sódio, foram os que apresentaram melhores resultados. (PINTO ATM, et al., 2013).

Indo ao encontro dessa afirmativa, evidências mostraram reduções estatisticamente significativas no índice de placa, inflamação gengival e sangramento na sondagem gengival, quando utilizado o Colgate Total que contém Triclosan e fluoreto de sódio, mostrando-se este um dentífrico abrangente que produziu uma redução significativa na gengivite, placa e sangramento (ROVER JA e LEU-WAI-SEE P, 2014).

A escolha do dentifrício Colgate Total para composição do kit de higiene bucal teve como base estudos laboratoriais recentemente dirigidos pela Colgate-Palmolive, os quais indicam que o dentifrício Colgate Total neutraliza mais $99 \%$ do Sars-Cov-2, vírus responsável pela COVID-19. Além disso, a pesquisa mostrou que os enxaguantes e spray bucal que contém em sua composição cloreto de cetilpiridínio, zinco, peroxido de hidrogênio e a clorexidina reduzem a quantidade de vírus na cavidade bucal (BRITISH DENTAL JOURNAL, 2021).

A inclusão do fio dental no kit proposto baseia-se em evidências que constatam a redução de gengivite quando associado ao uso do creme dental, mostrando benefícios desde a concepção até o controle de patologias de repercussão sistêmica, visto que a saúde periodontal poderá trazer benefícios não somente restritos à saúde bucal (ROVER JA e LEU-WAI-SEE P, 2014; RANDALL JP et al., 2015).

Vale nesse momento ilustrar que, de acordo com Andrade MRTC, et al. (2013), as crianças hospitalizadas com baixa frequência no uso de fio dental apresentam maior acumulo de placa e cálculo à medida que o tempo do tratamento avança. Kubo MM e Mialhe FL (2011) e Azcarate-Velázquez F, et al. (2017) afirmam que o uso do fio dental é a escolha mais adequada para a limpeza das áreas interproximais dos dentes, porém, age somente como uma complementação da escovação mecânica, sendo necessária uma ação conjunta e regular para o controle do biofilme.

Oliveira LAL, et al. (2020) relatam o uso bastante difundindo da clorexidina na odontologia, pois é uma importante substância antimicrobiana, efetiva contra bactérias Gram-positivas e Gram-negativas, e possui 
elevada substantividade. Somado a isso, em ensaio clínico randomizado realizado em indivíduos adultos sob ventilação mecânica, mostraram superioridade da clorexidina $0,12 \%$ associada à escovação quando comparada ao uso isolado. (DE LACERDA VIDAL CF, et al., 2017).

Segundo Cardona A, et al. (2017) destacam-se que há evidências da ineficiência da clorexidina na redução da severidade e na prevenção da mucosite. Nakonechna A, et al. (2014) relatam reações adversas ao uso da clorexidina em casos de hipersensibilidade.

Tunãs DM, et al. (2020) defendem que a solução de clorexidina a $0,12 \%$ não se faz eficaz na prevenção da transmissão da COVID-19, de modo que se considera importante que o paciente faça um bochecho com peróxido de hidrogênio a $1 \%$ ou lodopovidona a $0,2 \%$. Porém, Consolaro A, et al. (2013) destacam que o peróxido de hidrogênio pode causar ferimento e inflamação da mucosa e gengiva, além de ocasionar necrose das papilas gengivais, atuar na porosidade dos esmaltes dentários e contribuir para carcinogênese química que ocorre na boca, em todo o trato gastrointestinal e em outros órgãos.

Diante disso, de acordo com as recomendações do Centers for Disease Control and Prevention, a clorexidina a $0,12 \%$, cloreto de cetilperidine, óleos essenciais e iodopovidona podem ser utilizados como enxaguantes bucais antes da realização do procedimento, sendo preferível a permanência da utilização da clorexidina. A escolha da clorexidina compondo o kit de higiene bucal para bochecho reside no fato de ser uma substância bacteriostática e bactericida de amplo espectro e por constar na rede municipal de saúde. (GOMES DCA, et al., 2020).

É essencial que pacientes internados recebam orientação e higiene bucal por parte da equipe multidisciplinar, para que haja redução das infecções nosocomiais, especialmente as do trato respiratório superior, e compreendemos que a aquisição do kit, pelo baixo custo e elevado grau de contribuição comprova a importância do tratamento holístico. Entendemos ainda a necessidade de pesquisas para validação do kit e reforçamos a presença do cirurgião dentista compondo as equipes no âmbito hospitalar.

\section{REFERÊNCIAS}

1. AGUIAR ASW, et al. Atenção em saúde bucal em nível hospitalar: relato de experiência de integração ensino/serviço em odontologia. R. Eletr. de Extensão, 2010; (9): 100-110.

2. ANDRADE MRTC. Condições orais de crianças e adolescentes em hemodiálise: estudo clínico e laboratorial. Rio de Janeiro: UFRJ, 2013. 128p.

3. AZCARATE-VELÁZQUEZ F, et al. Effectiveness of flossing loops in the control of the gingival health. $\mathrm{J}$ Clin Exp Dent. 2017; 9(6): e756-61.

4. BARBOSA N. Importância do Cirurgião-Dentista no âmbito hospitalar: revisão narrativa da literatura. Research, Society and Development, 2020; 9(9): e575997622.

5. TOOTHPASTE AND MOUTHWASH INACTIVATE 99.9\% OF THE VIRUS THAT CAUSES COVID-19. 2020. In: BRITISH DENTAL JOURNAL. Disponível em: https://www.nature.com/articles/s41415-020-2476-8.pdf. Acesso em: 21 fev.2021.

6. BUSATO CA, et al. Utilização do hipoclorito de sódio na descontaminação de escovas dentais estudo in vitro. Rev. odontol. UNESP, 2015; 44(6): 335-339.

7. CARDONA A, et al. Efficacy of chlorhexidine for the prevention and treatment of oral mucositis in cancer patients: a systematic review with meta-analyses. J Oral Pathol Med, 2017.

8. CONSOLARO A. Mouthwashes with hydrogen peroxide are carcinogenic, but are freely indicated on the internet: warn your patients! Dental Press J. Orthod., 2013; 18(6).

9. DE LACERDA VIDAL CF, et al. Impact of oral hygiene involving tooth brushing versus chlorhexidine in the prevention of ventilator-associated pneumonia: a randomized study. BMC InfectDis, 2017; 31: 17(1): 112.

10. FRANCO AB, FRANCO AG. Atendimento odontológico em UTI's na presença de COVID-19. InterAm J Med Health, 2020; 3: e202003004.

11. GOMES DCA. Adaptação dos cirurgiões-dentistas frente à ameaça da COVID-19. Braz. J. of Develop., 2020; 6(9): 64449-64459.

12. GOMES SF, ESTEVES MC. Atuação do cirurgião-dentista na UTI: um novo paradigma. Rev. Bras. Odontol 2012; 69(1): 67-70.

13. GONÇALVES GH, et al. Contaminação, meios de desinfecção e armazenamento da escova dental revisão de literatura. Rev Inic Cient Ext, 2019; 2(4): 219-27. 
14. KUBO MM, MIALHE FL. Fio dental: da dificuldade ao êxito na remoção do biofilme interproximal. Arq Odontol, 2011; 47(1): 51-55.

15. MENEZES MLFV, et al. A importância do controle do biofilme dentário: uma revisão da literatura. Revista Eletrônica Acervo Saúde (REAS), 2020; 55: e3698.

16. NAKONECHNA A, et al. Immediate hypersensitivity to chlorhexidine is increasingly recognized in the United Kingdom. Allergology and Immunopathology, 2014; 42(1): 44-49.

17. NETO JMAS, et al. A atuação do cirurgião dentista no âmbito hospitalar: uma revisão de literatura. Revista Eletrônica Acervo Saúde (REAS), 2019; 35: e1616.

18. NOGUEIRA ES, et al. Prescrição de higiene bucal nos prontuários de pacientes internados emu ma cidade da Amazônia. Rev Assoc Paul Cir Dent, 2014; 68(3): 214-8.

19. OLIVEIRA LAL, et al. Eficácia das técnicas de higiene oral em pacientes internados em unidades de terapia intensiva. Revista Odontológica de Araçatuba, 2020; 41(3): 22-28.

20. PINTO ATM, et al. Atividade Antimicrobiana de Dentifrícios Fitoterápicos Contra Streptococcus mutans e Staphylococcus aureus. UNOPAR Cient., Ciênc. Biol. Saude, 2013; 15(4).

21. QUEIROZ FS, et al. Avaliação do perfil de armazenamento e descontaminação das escovas dentais. Revista de Odontologia da UNESP, 2013; 42(2).

22. RANDALL JP, et al. Antibacterial activity of fluoride compounds and herbal toothpastes on Streptococcus mutans: an in vitro study. Aust Dent J, 2015; 60(3): 368-74.

23. ROVER JA, LEU-WAI-SEE P. Role of Colgate Total toothpaste in helping control plaque and gingivitis. Am J Dent, 2014; 27(3): 167-70.

24. TUÑAS DM. Coronavirus Disease 2019 (COVID-19): A Preventive Approach to Dentistry. Rev. Bras. Odontol., 2020; 77: e1766. 